\title{
The Importance of the World Health Organization Sugar Guidelines for Dental Health and Obesity Prevention
}

\author{
Joao Breda ${ }^{a}$ Jo Jewell ${ }^{a} \quad$ Amélie Keller ${ }^{b}$ \\ ${ }^{a}$ Nutrition, Physical Activity and Obesity Programme, Division of Noncommunicable Diseases and Promoting Health \\ through the Life-Course, World Health Organization Regional Office for Europe, Copenhagen, Denmark; ${ }^{\mathrm{b}}$ Research \\ Unit for Dietary Studies, The Parker Institute, Bispebjerg og Frederiksberg Hospital, Capital Region, Frederiksberg, \\ Denmark
}

\section{Keywords}

Sugar · Non-communicable disease · Dental health · Obesity

\section{Abstract}

The World Health Organization (WHO) recommends a reduced intake of free sugars throughout the life course (strong recommendation) with a reduction of free sugars intake to less than $10 \%$ of the total energy intake (strong recommendation) and preferably below $5 \%$ of the total energy intake (conditional recommendation) in both adults and children. Available data clearly show that people already consume significantly more sugar than they should, increasing the risk for dental caries, overweight and obesity. The WHO recommendations are intended for use by the policy makers as a benchmark for assessing intake of sugars by populations and as a driving force for policy change. To create a favorable environment, enabling the overall amount of free sugar intake to be as low as possible and to reduce the frequency of consumption of sugar-rich foods, a range of public health interventions is advised.

C 2018 The Author(s)

Published by S. Karger AG, Basel

\section{KARGER}

E-Mail karger@karger.com www.karger.com/cre
The World Health Organization (WHO) recommends a reduced intake of free sugars ${ }^{1}$ throughout the life course (strong recommendation ${ }^{2}$ ) with a reduction of free sugars intake to less than $10 \%$ of the total energy intake (strong recommendation) and preferably below $5 \%$ of the total energy intake (conditional recommendation $^{3}$ ) in both adults and children (WHO guideline on sugars intake for adults and children). These recommendations were based on the totality of evidence systemati-

${ }^{1}$ Free sugars include monosaccharides and disaccharides added to foods and beverages by the manufacturer, cook or consumer, and sugars naturally present in honey, syrups, fruit juices and fruit juice concentrates (WHO guideline on sugars intake for adults and children).

${ }^{2}$ Strong recommendations indicate that "the desirable effects of adherence to the recommendation outweigh the undesirable consequences." This means that "the recommendation can be adopted as policy in most situations" [Blas et al.].

${ }^{3}$ Conditional recommendations are made when there is less certainty "about the balance between the benefits and harms or disadvantages of implementing a recommendation." This means that "policy-making will require substantial debate and involvement of various stakeholders" for translating them into action [Blas et al.].

This article is based on a contribution to the Joint ORCA-EADPH Symposium on Sugar and Oral Health, July 6, 2016.

Jo Jewell, Technical Officer

Nutrition, Physical Activity and Obesity Programme, Division of Noncommunicable Diseases and Promoting Health through the Life-Course

World Health Organization Regional Office for Europe, Marmorvej 51

DK-2100 Copenhagen (Denmark), E-Mail jewellj@ who.int 
cally reviewed regarding the relationship between free sugars intake and body weight and dental caries (WHO| Guideline Sugars intake for adults and children i Sugars intake for adults and children). Given the importance of this evidence, and the role of sugar reduction in helping to address the burden of dental caries, a representative of the WHO (J.J.) was invited to address the joint ORCA/ EADPH symposium on sugar and oral health in 2016. Since then, further work has been published on sugar and health. This commentary serves to reflect upon the WHO's recommendations and provide an update on the available evidence.

Most dietary intake surveys currently capture data on the intake of added sugars rather than free sugars; added sugars are more narrowly defined than free sugars, indicating that the level of free sugars intake is likely to be even higher than reported in most national data. In Europe, the consumption of added sugars ${ }^{4}$ currently contributes between $7-11$ and $11-17 \%$ of the total energy intake in adults and children, respectively [Azaïs-Braesco et al., 2017]. Worldwide, data suggest that added sugar intake begins to rise from the age of 1 year, and is highest among school-age children and adolescents compared to younger children or adults [Newens and Walton, 2016]. Sweet products (i.e., cakes, biscuits, pastries, confectionary, jam/honey, ice cream, table sugar), beverages (i.e., sugar-sweetened beverages and fruit nectars excluding fruit juice) and dairy products (i.e., yoghurts, milk-based desserts) contribute most to added sugar intake in both adults and children [Azaïs-Braesco et al., 2017; Bailey et al., 2018]. In addition to the definitional differences between added sugars and free sugars, added sugars (and foods rich in added sugars) are also the items that are most underreported by both adults and children in dietary surveys [Newens and Walton, 2016]. This means that the percentage of total energy intake coming from free sugars is likely to be even higher. Hence, underestimated or not, the available data clearly show that people already consume significantly more sugar than they should.

Dental caries is an international public health challenge with $\leq 80 \%$ of the world's population affected, and is the most common chronic infectious disease of childhood. The negative health effects of dental caries are cumulative and track from childhood to adulthood [Broadbent et al., 2008]. Dental caries are caused by the interac-

\footnotetext{
${ }^{4}$ Added sugar include monosaccharides and disaccharides added to foods and beverages, cook or consumer.
}

tion of bacteria, mainly Streptococcus mutans, and sugary foods on tooth enamel. Although tooth decay can be conceptualized as a microbial disease, dietary sugar plays a crucial role and is considered to be the most important risk factor [Dülgergil et al., 2013; Moynihan, 2016]. To inform the 2015 WHO guidelines on sugar, WHO commissioned a systematic review about sugar intake and dental caries [Moynihan, and Kelly, 2014]. This review included 3 interventions, 8 cohorts, 20 population, and 24 cross-sectional studies with most studies conducted among children. The majority of studies among children and all studies among adults reported at least one positive association between sugars and caries. The review concluded that there was moderate quality evidence showing that caries is lower when free sugars intake is below $10 \%$ of the total energy intake. In addition, the risk of caries could be further reduced when free sugars intake is below $5 \%$; however, the evidence was judged to be of very low quality.

Overweight and obesity trends are also rising worldwide. A recent study published in the Lancet shows a tenfold increase in childhood and adolescent obesity between 1975 and 2016 [Abarca-Gómez et al., 2017]. In Europe, the rates of overweight and obesity are also high, with $50-70 \%$ of adults being overweight or obese. Overweight and obesity are also highly prevalent among children and adolescents with one third of children aged 6-9 years being overweight or obese [Wijnhoven et al., 2007], and a prevalence of overweight and obesity comprised between $11-33,12-27$ and $10-23 \%$ for children aged 11, 13 and 15 years respectively (Regional Committee for Europe 64th Session, 2015). The systematic review by Te Morenga (2012), which was commissioned by the WHO and informed the 2015 guidelines on sugar, included 30 trials and 38 cohort studies, of low and moderate quality, of free living people with ad libitum diets. The review concluded that intake of free sugars or sugar sweetened beverages was a determinant of body weight, with increased sugar intake leading to weight gain and inversely [Te Morenga et al., 2012]. Evidence from other systematic reviews and meta-analyses also suggest a direct association between intake of sugarsweetened beverages and weight gain, overweight and obesity [Keller, and Bucher Della Torre, 2015; Malik et al., 2013].

In addition to dental caries and body weight, excessive sugar consumption from foods and beverages high in added sugars has been associated with an increased risk of type 2 diabetes [de Koning et al., 2011], cardiovascular diseases [Malik et al., 2010; Yu et al., 2018; Keller et al., 2014], some 
cancers [Fuchs et al., 2014; Van Blarigan, and Meyerhardt, 2015; Port et al., 2012] as well as non-alcoholic fatty liver disease [Wijarnpreecha et al.,2016]. In addition, emerging research suggest that diet high in sugars may increase the risk of developing dementia such as Alzheimer disease [An et al., 2018; Pase et al., 2017]. Although, trends between added sugar intake and socioeconomic status (SES) in Europe are not as clear as in the US [Azaïs-Braesco et al., 2017], data from the UK show that low SES is associated with higher added sugar intake. Individuals from lower SES also experience a higher prevalence of tooth decay and obesity and its health consequences (Sugar Reduction, The Evidence for Action, 2015).

The WHO recommendations are intended for use by the policy makers as a benchmark when assessing intake of sugars by populations and as a driving force for policy change. To create a favorable environment, enabling the overall amount of free sugars intake to be as low as possible and to reduce the frequency of consumption of sugar-rich foods, developing and implementing a range of public health interventions is advised. Nutrition labeling, consumer education, regulation of marketing of food and non-alcoholic beverages that are high in free sugars, and fiscal policies targeting foods and beverages that are high in free sugars have been recommended as policy actions to reduce sugar availability and intake. In addition, policy measures that engage food retailers and caterers in reformulating and decreasing the portion size of common daily consumed processed food contributing most to sugar intake should be implemented for the improvement of populations' health status through improvement of products' nutritional properties (Global Action Plan for the Prevention and Control of Noncommunicable Diseases iii WHO Library Cataloguing-In-Publication Data, 2013; WHO| Guideline Sugars intake for adults and children i Sugars intake for adults and children).

\section{Disclosure Statement}

Joao Breda and Jo Jewell are staff members of the World Health Organization Regional Office for Europe. The authors are responsible for the views expressed in this publication and they do not necessarily represent the decisions or stated policy of WHO. The authors declare no conflicts of interest.

\section{Author Contributions}

All authors contributed to the text and reviewed the final version.

\section{References}

Abarca-Gómez L, Abdeen ZA, Hamid ZA, AbuRmeileh NM, Acosta-Cazares B, Acuin C, et al: Worldwide trends in body-mass index, underweight, overweight, and obesity from 1975 to 2016: a pooled analysis of $2416 \mathrm{popu}-$ lation-based measurement studies in 128.9 million children, adolescents, and adults. Lancet 2017;390:2627-2642.

An Y, Varma VR, Varma S, Casanova R, Dammer E, Pletnikova O, et al: Evidence for brain glucose dysregulation in Alzheimer's disease. Alzheimer's Dement 2018;14:318-329.

Azaiis-Braesco V, Sluik D, Maillot M, Kok F, Moreno LA: A review of total \& added sugar intakes and dietary sources in Europe. Nutr J 2017;16:6.

Bailey RL, Fulgoni VL, Cowan AE, Gaine PC: Sources of added sugars in young children, adolescents, and adults with low and high intakes of added sugars. Nutrients 2018;10. pii:E102.

Van Blarigan EL, Meyerhardt JA: Role of physical activity and diet after colorectal cancer diagnosis. J Clin Oncol 2015;33:1825-1834.

Blas E, Koller T, Magar V, Thomas R, Vogel J, Abou-Setta A, et al: WHO Library Cataloguing-in-Publication Data WHO handbook for guideline development. Peer Rev Med Heal Organ World Heal Organ [cited April 29, 2018]; 1. www.who.int/about/licensing/copyright_form/en/index.html.

Broadbent JM, Thomson WM, Poulton R: Trajectory patterns of dental caries experience in the permanent dentition to the fourth decade of life. J Dent Res 2008;87:69-72.

Çolak H, Dülgergil ÇT, Dalli M, Hamidi MM: Early childhood caries update: a review of causes, diagnoses, and treatments. J Nat Sci Biol Med 2013;4:29-38.

Fuchs MA, Sato K, Niedzwiecki D, Ye X, Saltz LB, Mayer RJ, et al: Sugar-sweetened beverage intake and cancer recurrence and survival in CALGB 89803 (Alliance). PLoS One 2014; 9:e99816.

Global Action Plan for The Prevention and Control of Noncommunicable Diseases iii Who Library Cataloguing-In-Publication Data, 2013 [cited April 29, 2018]. www.who.int/ about/licensing/copyright_form/en/index. html.

Keller A, Bucher Della Torre S: Sugar-sweetened beverages and obesity among children and adolescents: a review of systematic literature reviews. Child Obes 2015;11:338-346.
Keller A, Heitmann BL, Olsen N: Sugar-sweetened beverages, vascular risk factors and events: a systematic literature review. Public Health Nutr 2014;18:1-10.

de Koning L, Malik VS, Rimm EB, Willett WC, $\mathrm{Hu}$ FB: Sugar-sweetened and artificially sweetened beverage consumption and risk of type 2 diabetes in men. Am J Clin Nutr 2011; 93:1321-1327.

Malik VS, Pan A, Willett WC, Hu FB: Sugarsweetened beverages and weight gain in children and adults: a systematic review and metaanalysis. Am J Clin Nutr 2013;98:1084-1102.

Malik VS, Popkin BM, Bray GA, Despres JP, Willett WC, Hu FB: Sugar-sweetened beverages and risk of metabolic syndrome and type 2 diabetes: a meta-analysis. Diabetes Care 2010; 33:2477-2483.

Te Morenga L, Mallard S, Mann J: Dietary sugars and body weight: systematic review and metaanalyses of randomised controlled trials and cohort studies. BMJ 2012;346:e7492.

Moynihan P: Sugars and dental caries: evidence for setting a recommended threshold for intake. Adv Nutr 2016;7:149-156.

Moynihan PJ, Kelly SA: Effect on caries of restricting sugars intake. J Dent Res 2014;93:8-18. 
Newens KJ, Walton J: A review of sugar consumption from nationally representative dietary surveys across the world. J Hum Nutr Diet 2016;29:225-240

Pase MP, Himali JJ, Jacques PF, DeCarli C, Satizabal CL, Aparicio H, et al: Sugary beverage intake and preclinical Alzheimer's disease in the community. Alzheimer's Dement 2017; 13:955-964.

Port AM, Ruth MR, Istfan NW: Fructose consumption and cancer. Curr Opin Endocrinol Diabetes Obes 2012;19:367374.
Regional Committee for Europe 64th Session. Eur Food Nutr Action Plan 2015 [cited April 29, 2018].http://www.euro.who.int/_data/assets/pdf_file/0008/253727/64wd14e_FoodNutAP_140426.pdf.

Sugar Reduction the Evidence for Action, 2015 [cited April 30, 2018]. www.gov.uk/phe.

WHO guideline on sugars intake for adults and children [cited April 29, 2018]. http://www. who.int/nutrition/publications/guidelines/ sugars_intake/en/.

Wijarnpreecha K, Thongprayoon C, Edmonds PJ, Cheungpasitporn W: Associations of sug- ar-and artificially sweetened soda with nonalcoholic fatty liver disease: a systematic review and meta-analysis. QJM 2016;109:461466

Wijnhoven T, Van Raaij J, Breda J: WHO European Childhood Obesity Surveillance Initiative, 2007 [cited April 29, 2018]. http://www.euro.who. int/_data/assets/pdf_file/0004/258781/COSI-report-round-1-and-2_final-for-web.pdf.

Yu Z, Ley SH, Sun Q, Hu FB, Malik VS: Crosssectional association between sugar-sweetened beverage intake and cardiometabolic biomarkers in US women. Br J Nutr 2018;119:570-580. 